\title{
Root mediated uptake of Salmonella is different from phyto-pathogen and associated with the colonization of edible organs
}

\author{
Kapudeep Karmakar ${ }^{1}$, Utpal Nath ${ }^{1}$, Karaba N. Nataraja ${ }^{3}$ and Dipshikha Chakravortty ${ }^{1,2^{*}}$ (1)
}

\begin{abstract}
Background: Pre-harvest contamination of fruits and vegetables by Salmonella in fields is one of the causes of food-borne outbreaks. Natural openings like stomata, hydathodes and fruit cracks are known to serve as entry points. While there are reports indicating that Salmonella colonize and enter root through lateral root emerging area, further investigations regarding how the accessibility of Salmonella to lateral root is different from phytopathogenic bacteria, the efficacy of lateral root to facilitate entry have remained unexplored. In this study we attempted to investigate the lateral root mediated entry of Salmonella, and to bridge this gap in knowledge.
\end{abstract}

Results: Unlike phytopathogens, Salmonella cannot utilize cellulose as the sole carbon source. This negates the fact of active entry by degrading plant cellulose and pectin. Endophytic Salmonella colonization showed a high correlation with number of lateral roots. When given equal opportunity to colonize the plants with high or low lateral roots, Salmonella internalization was found higher in the plants with more lateral roots. However, the epiphytic colonization in both these plants remained unaltered. To understand the ecological significance, we induced lateral root production by increasing soil salinity which made the plants susceptible to Salmonella invasion and the plants showed higher Salmonella burden in the aerial organs.

Conclusion: Salmonella, being unable to degrade plant cell wall material relies heavily on natural openings. Therefore, its invasion is highly dependent on the number of lateral roots which provides an entry point because of the epidermis remodeling. Thus, when number of lateral root was enhanced by increasing the soil salinity, plants became susceptible to Salmonella invasion in roots and its transmission to aerial organs.

Keywords: Lateral roots, Epidermis remodeling, Salmonella, Tomato, Salinity

\section{Background}

Salmonella serovars are recognized as important foodborne pathogens associated with poultry $[1,2]$ and raw plant products $[3,4]$. There has been an increase in human infections with various serovars linked to raw produce [5]. The raw plant products get contaminated during shipping and processing [6]. However, in the last few decades, reports have shown the evidence of pre-harvest

\footnotetext{
*Correspondence: dipa@iisc.ac.in

'Department of Microbiology and Cell Biology, Indian Institute of Science, Bangalore 560012, India

${ }^{2}$ Centre for Biosystems Science and Engineering, Indian Institute of Science, Bangalore 560012, India

Full list of author information is available at the end of the article
}

contamination of salad vegetables $[7,8]$. Irrespective of the species, plants grown in Salmonella-contaminated soil became colonized with the organism $[9,10]$.

Various biotic and abiotic components play an important role in successful colonization of Salmonella in roots. De-novo factors like flagella [11], fimbriae [12], and exopolysaccharides [13] are known to enable pathogen to colonize the host. Presence of a phytopathogen like Xanthomonas [14] in vicinity can lead to higher coloniza tion of Salmonella. But, beneficial organisms like Sinorhizobium meliloti is known to reduce the burden of Salmonella in plants [15]. Gu et al reported the presence of

(C) The Author(s). 2018 Open Access This article is distributed under the terms of the Creative Commons Attribution 4.0 International License (http://creativecommons.org/licenses/by/4.0/), which permits unrestricted use, distribution, and 
Salmonella in the vasculature of the leaves and the fruits without causing any visible symptoms [16].

The entry point of Salmonella in plants is well-studied. They can enter the aerial organs through the openings such as stomata [17], hydathodes [18] and fruit cracks [19]. Unlike aerial organs, below ground organs are in direct contact with the contaminated soil. Salmonella, can become systemic after its entry into the plant and can colonize the aerial organs [20,21]. Cooley et al. has shown the movement of Salmonella Newport and E.coli O157:H7 as an epiphytic migrant. They have also reported that E.coli O157:H7 can enter the vasculature of the plant but not Salmonella Newport. Lateral root emerging areas with epidermal breakage, were shown to be colonized with these organisms and flagella aids in migration to these regions [22]. Many bacteria and fungi utilize this opening for getting access to root tissues [23, 24]. While there are reports indicating that lateral root emerging regions are the site of Salmonella entry and colonization [22, 25], the mechanism of entry is not well explored. Investigations regarding how the accessibility to lateral root for Salmonella is different from phyto-pathogens and the possibilities such as specific induction of lateral root formation by the bacteria have remained unexplored. The aim of the study is to understand the role of the lateral root in mediating Salmonella entry in a more elusive way. We used wild-type Arabidopsis with Col-0 accession and tomato (cultivar INDAM 535) as plant model systems. As an extension of the study, we have examined soil stress factor (salinity) in transmission of Salmonella from soil to the aerial organs.

\section{Results}

\section{Salmonella colonization of root is different from phyto-} pathogen colonization

Since plant cell wall and middle lamella are chemically composed of cellulose and pectin respectively, phytopathogens producing cellulases and pectinases can degrade and enter the host tissues [26]. In order to understand Salmonella mediated active degradation of these polysaccharides, we examine the growth profile of Salmonella in minimal media with cellulose and pectin as sole carbon source. Unlike plant pathogens, like $P$. syringae, $R$. solanacearum and $X$. oryzae, Salmonella is incapable of utilizing cellulose/pectin (Additional file 1: Figure S1A-B). Thus active invasion by degrading cell wall of the plant is not possible. Tomato roots inoculated with these organisms were observed to study pattern of colonization inside the root tissue. We observed that phytopathogens can cause tissue degradation but Salmonella cannot (Additional file 1: Figure S1C-E). Root cells in Salmonella and Ralstonia mutant $\Delta h r p B$ (deficint in type III secretion system) infected plants maintain their identity (Additional file 1: Figure S1E-F). Concomitantly, we observed higher CFU of phytopathogens like Ralstonia, Xanthomonas and Pseudomonas as compared to Salmonella in the root tissue but not in rhizoplane (Additional file 1: Figure S1G). We did not see any growth defect of these organisms in concentrated tomato root exudates (Additional file 1: Figure $\mathrm{S} 1 \mathrm{H}$ ), thus confirming that plant derived secretary metabolites is not responsible for lower CFU of Salmonella. Therefore, we examined the entire root thoroughly using tile scan in confocal microscope. We observed that there was very high colonization of Salmonella (Fig. 1a [1-8]) in the lateral root emerging regions as compared to the other regions (Fig. 1A [i-iii]). However, we did not find this pattern in phytopathogen Ralstonia, which equally colonizes the lateral root emerging and non-emerging sites (Additional file 1: Figure S1I). Beneficial organisms like mycorhizal fungi are known to enter through these lateral root emerging sites [27]. Plant growth promoting Rhizobacteria (PGPR) are known to enhance root biomass by producing various phyto-hormones and trigger root development [28]. However, to understand whether the Salmonella entry via LR is a chance event or triggered event, we counted the number of LR before and after Salmonella treatment and compared it with the un-inoculation control. Unlike PGPRs like G. diazotrophicus (endophyte) and P. fluorescence (rhizospheric and surface colonizing bacteria), Salmonella cannot induce LR formation in Arabidopsis (Fig. 1b).

To investigate the efficacy of lateral root dependent colonization, we used an Arabidopsis mutant axr1-3 (from TAIR) which produces fewer lateral roots [29]. However, exogenous auxin can induce lateral roots in axr1-3. [29] We use naphthalene acetic acid (NAA), a synthetic auxin, to induce lateral root formation. Upon NAA treatment, in axr1-3 we observed concentration dependent increase in number of lateral roots. Lateral roots in Col-0 on the other hand, increases but drops drastically beyond $100 \mathrm{nM}$ NAA (Additional file 2: Figure S2A). These NAA treated roots were dipped in Salmonella suspension to analyze the colonization. Upon induction of lateral root in axr1-3 with NAA, Salmonella colonization was significantly enhanced (Fig. 1c). On the contrary, Col-0 produced fewer lateral roots upon $1 \mu \mathrm{M}$ NAA treatment, thus showing less colonization (Fig. 1c). We plotted endophytic CFU as a function of number of lateral root and observed a high correlation $\left(R^{2}=0.729\right.$ at $95 \%$ confidence interval $\left.(\mathrm{CI})\right)$ for Salmonella, but $E$. coli DH5 $\alpha$ (non-phytopathogen control; $\mathrm{R}^{2}=$ 0.253 at $95 \% \mathrm{CI}$ ) had low correlation with the number of lateral roots (Fig. 1d). P. syringae also had lower colonization (phytopathogen control; $\mathrm{R}^{2}=0.309$ at $95 \% \mathrm{CI}$ ) (Additional file 2: Figure S2C). The low correlation for P.syringae could be due to its ability to degrade the cell wall and enter the 

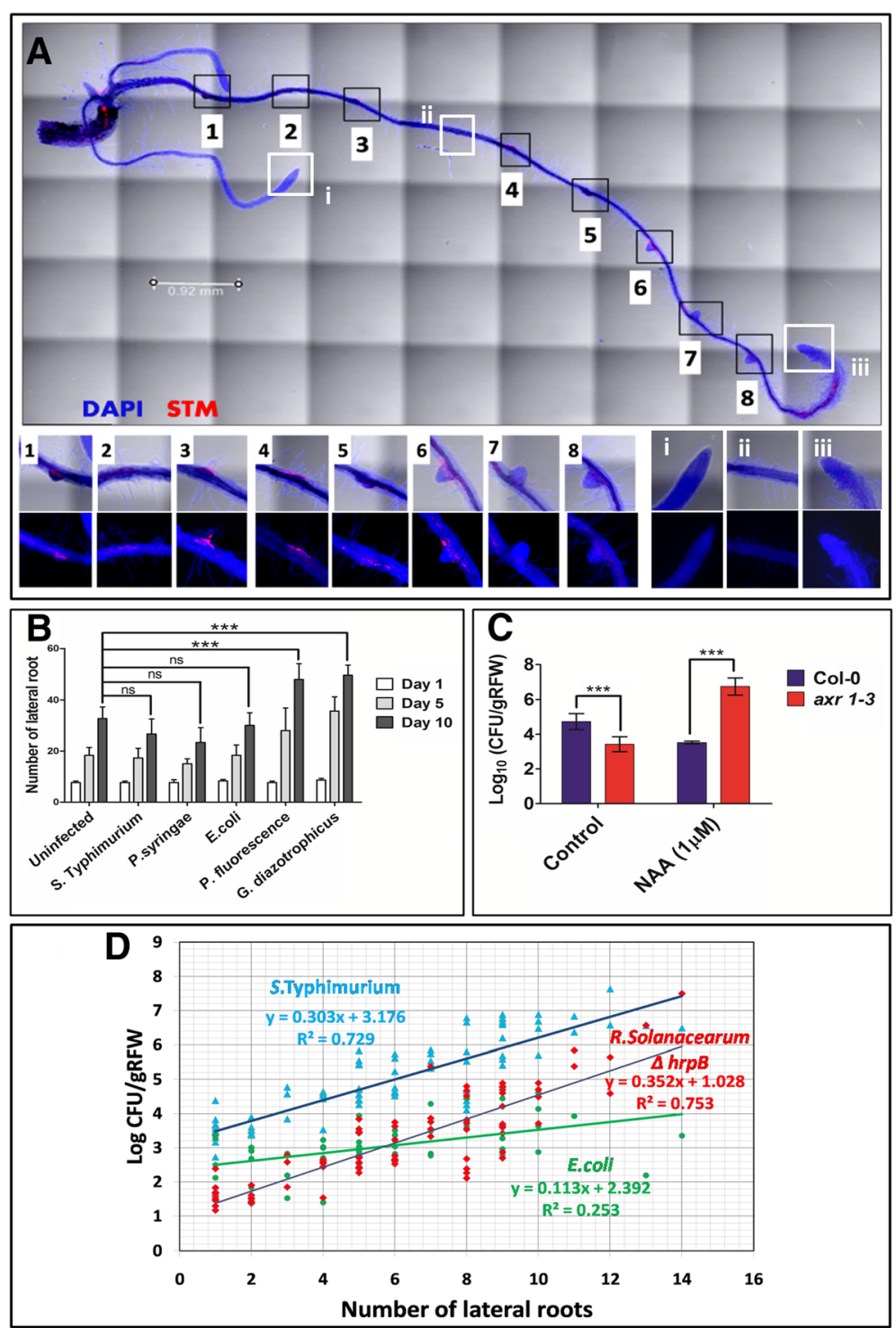

Fig. 1 In-vitro colonization of Salmonella is dependent on lateral roots. (a) Representative image depicting Salmonella (mcherry tagged) colonization near the lateral root emerging area. Root is stained with DAPI. (b) Number of lateral roots upon inoculation of various organisms on Day 1, 5 and 10. ANOVA was used to analyze the data. The comparison shown is between uninfected and infected plants at 10th day. ${ }^{* * *}=P<0.001$; ns $=$ not significant. (c) Salmonella colonization upon inhibition and induction of lateral roots by NAA for Col-0 and axr 1-3 respectively. ANOVA was used to evaluate the significance. ${ }^{* *}=P<0.001$. Each experiment was repeated 3 times with 5 replicate each. (d) Correlation of Salmonella colonization with lateral root (at $95 \% \mathrm{Cl}$ ). Ralstonia solanacearum $\Delta$ hrpB was used as positive control and E.coli was used as non phytopathogenic bacteria control respectively. $N=50$ for each organism for calculating correlation

root tissue through any part of the root (as an alternative to lateral root emerging sites). Ralstonia $\triangle h r p B$ endophytic CFU showed high correlation with number of lateral roots (Fig. 1d) and was used as a positive control $\left(R^{2}=0.762\right.$ at 95\% CI). The rhizoplanic colonization (on the root surface) remains unaffected by the lateral root number for Salmonella, E.coli DH5 $\alpha$ and P.syringae (Additional file 2: Figure S2D-F). Thus lateral root emergence can efficiently serve as gateway to the internal tissue of the plants for Salmonella without affecting its surface colonization.

\section{In-situ colonization of Salmonella is dependent on lateral roots}

Based on the in-vitro observations we carried out a similar experiment in soil with a modification that soil was pre-treated with Salmonella and 10 days old Col-0 or axr1-3 seedlings were transplanted. The bacterial burden in rhizoplane and root tissue was assessed. Interestingly, the CFU in the rhizoplane for both Col-0 and axr1-3 were not different, nevertheless, the CFU in root tissue was significantly higher for Col-0 after 14 and 20 days 
(Fig. 2a). A significant increase in invasion index (Log CFU root tissue/Log CFU rhizoplane) in a time dependent manner was observed for Col-0 but not for axr1-3 (Fig. $2 \mathrm{~b}$ ). To further understand the role of lateral roots as an entry point, we co-transplanted Col- 0 and axr $1-3$ in same soil pretreated with Salmonella. Out of 20 experiments, data from 17 experiments were plotted and analyzed because either or both the pair was dead till 20th day in remaining pots. The mean CFU in root tissue for Col-0 was significantly higher as compared to axr1-3 in same pot (Fig. 2c). Thus, irrespective of the plant (wild type or axr1-3) grown on same soil, Salmonella colonization depends solely on the number of lateral roots produced by the plant.

Lateral root originates from the pericycle cells because of auxin reflux between pericycle and endodermis [30] but its emergence requires cooperation from the neighboring cells like endodermis [31]. This leads to the weakening of paracellular junction of endodermis to allow lateral root to cross the endodermis. The auxin signal spreads from the lateral root to the cortex and epidermis resulting in coordinated remodeling of these layers [32]. Therefore, lateral root emergence is always accompanied by epidermis remodeling, wherein epidermis opens up for lateral root emergence [33].This results in, a cavity formation between primary root and lateral root (Fig. 2d; Additional file 3: Figure S3A-B).We took optical sections of the emerging lateral root, previously inoculated with GFP-tagged Salmonella, and a 3-D image was generated. The bacteria were located as deep as $52 \mu \mathrm{m}$ which approximately correspond to the region between endodermis and pericycle in the root under observation (Additional file 3: Figure S3C-D). Transverse section of the arabidopsis root showed the entry of Salmonella through the remodeled epidermis and colonized the region between the epidermis and cortex (Fig. 2e). The same results were observed in soil grown tomato plants where Salmonella was able to colonize the lateral root emerging area (Fig. $2 \mathrm{f}$ i). Subsequent optical sections showed the epidermis remodeling and Salmonella entry between the epidermis and cortical cell layer (Fig. $2 \mathrm{f}$ ii and iii). Hence, we conclude that Salmonella can enter the root tissue via the opening created between main root and lateral root and can penetrate the deeper layer of the root.

\section{Mild salinity induced lateral root renders the plant susceptible to Salmonella invasion}

Since lateral roots facilitate the entry of Salmonella into the root tissues, we examined conditions which can induce lateral root formation. Abiotic stress factors like salinity are known to cause morphogenetic changes in root $[34,35]$. In order to check the affect of salinity towards root development and colonization of Salmonella, 7 day old Arabidopsis seedlings were transferred to MS agar plate supplemented with varying concentrations of $\mathrm{NaCl}$. Lateral root formation was significantly increased in Arabidopsis seedlings till $50 \mathrm{mM} \mathrm{NaCl}$ beyond which there was not much increase (Fig. 3a; Additional file 4: Figure S4). This was in accordance with increased CFU/ g RFW (Fig. 3b). $100 \mathrm{mM} \mathrm{NaCl}$ treated plants were used as negative control as they we treated with stressor but do not induce lateral roots. Concomitantly, we observed an increase in CFU with varying salt concentrations in a dose dependent manner (Fig. 3c). In soil, we used varying concentration of $\mathrm{NaCl}$ to enhance the electrical conductivity and 20 days old tomato seedlings were transplanted. The number of lateral root increases with increase in $\mathrm{NaCl}$ concentration till $25 \mathrm{mg} \mathrm{NaCl} / \mathrm{g}$ soil, beyond which it decreases (Fig. 3d). The concentration of $\mathrm{NaCl}$ used in this study ( $25 \mathrm{mg} \mathrm{NaCl} / \mathrm{g}$ soil) corresponds to the electrical conductivity of $2.24 \mathrm{mS} / \mathrm{cm}$ which is mild stress for tomato [36]. We observed increase in CFU as the salt concentration was raised from 0 to $25 \mathrm{mg} / \mathrm{g}$ soil (Additional file 5: Figure S5). We examined the fruits from infected plants for estimating Salmonella burden. The percentage of the fruits infected with Salmonella was higher in the plant grown in saline soil as compared to the control soil (Additional file 6: Figure S6). Fruits obtained from these plants had enhanced Salmonella burden than those grown on normal soil (Fig. 3e). Thus we conclude that salinity treatment increases the risk of Salmonella colonization on roots and its transmission to the fruits.

\section{Discussion}

In the past few decades, the incidence of human infection by enteric bacteria through the consumption of contaminated salad has increased [37]. Plants can be contaminated during crop growth i.e., before harvest through soil. In soil, Salmonella is known to survive for 300 days [38]. Greene et al reported that Salmonella enters tomato field through contaminated irrigation water [7]. Phytopathogen like Ralstonia and Xanthomonas produce cellulase (endoglucanse) [39, 40] and polygalacturonase (pectin methyl esterase and pectate lyase) secreted by their type III secretion system [41] and invade the plant root tissue. We screened phyto-pathogens like Ralstonia solanacearum, Xanthomonas oryzae and Pseudomonas syringae for their growth in cellulose or pectin as sole carbon source. These organisms degrade the plant tissues with cellulase or pectinase whereas Salmonella was unable to hydrolyze cellulose and pectin.

Pathogens utilize various natural openings to enter the host tissues. Leaves have specialized structures like stomata and hydathodes, but roots lack such natural openings. However epidermis remodeling during lateral root emergence can be utilized by microorganisms to gain access into the root tissues [24]. It was reported earlier that 

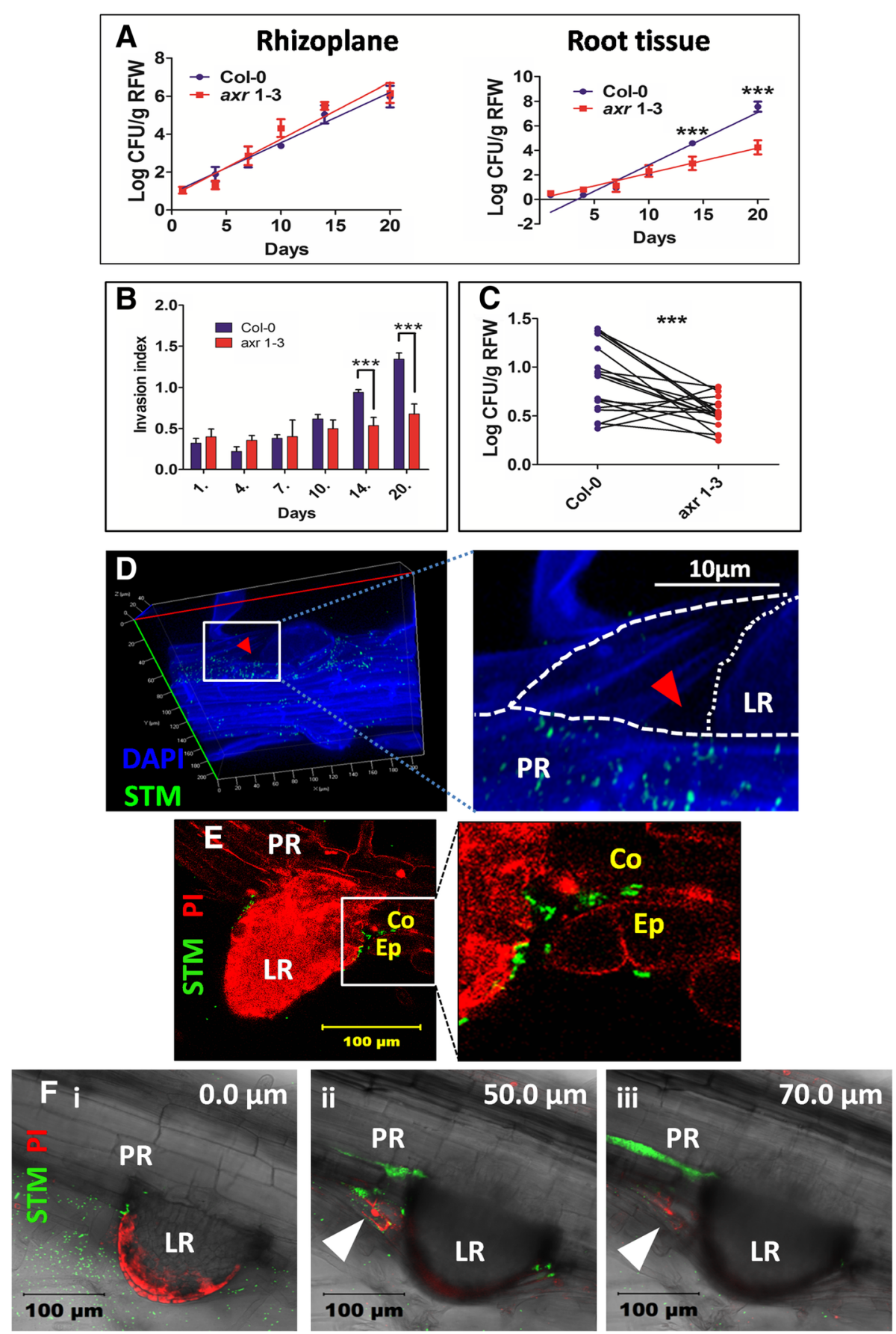

Fig. 2 In-situ colonization of Salmonella is dependent on lateral roots. (a) Colonization of Salmonella in rhizoplane (left) and root tissue (right) of Col-0 and axr1-3 grown in soil. ANOVA was used to analyze the data. ${ }^{* * *}=P<0.001 ; \mathrm{ns}=$ not significant. Best fit line was plotted (at $95 \% \mathrm{Cl}$ ). (b) Invasion index (Log CFU root tissue/Log CFU rhizoplane) for Col-0 and axr 1-3 was plotted over different days. One way ANOVA was used to evaluate the significance. ${ }^{* * *}=P<0.001$. Each experiment was repeated 3 times with 3 replicate each. (c) One-to-one correlation for root tissue colonization upon co-transplantation of Col-0 and axr 1-3 in same pot containing Salmonella ( $10^{8} \mathrm{cell} / \mathrm{s} / \mathrm{g}$ soil). The experiment was repeated 3 times with 5 replicate each. Wilcoxan rank test was used to analyse the data. ${ }^{* *}=\mathrm{P}<0.001$. (d) Representative image showing remodeling of epidermis and lateral root emergence with Salmonella colonization. The red arrow head shows the space created when lateral root (LR) emerges from primary root (PR). (e) Representative image of transverse section of Arabidopsis root showing Salmonella in between the epidermis (Ep) and cortical cells (Co). (f) Transverse section of emerged lateral root in tomato with 3 representative Z-stacks: i. Surface view of lateral root (LR) and primary root (PR); ii. Remodeling of epidermis (White arrow head) and Salmonella entry through the space between PR and LR; iii. Salmonella colonization in between epidermis and cortical cell layer 

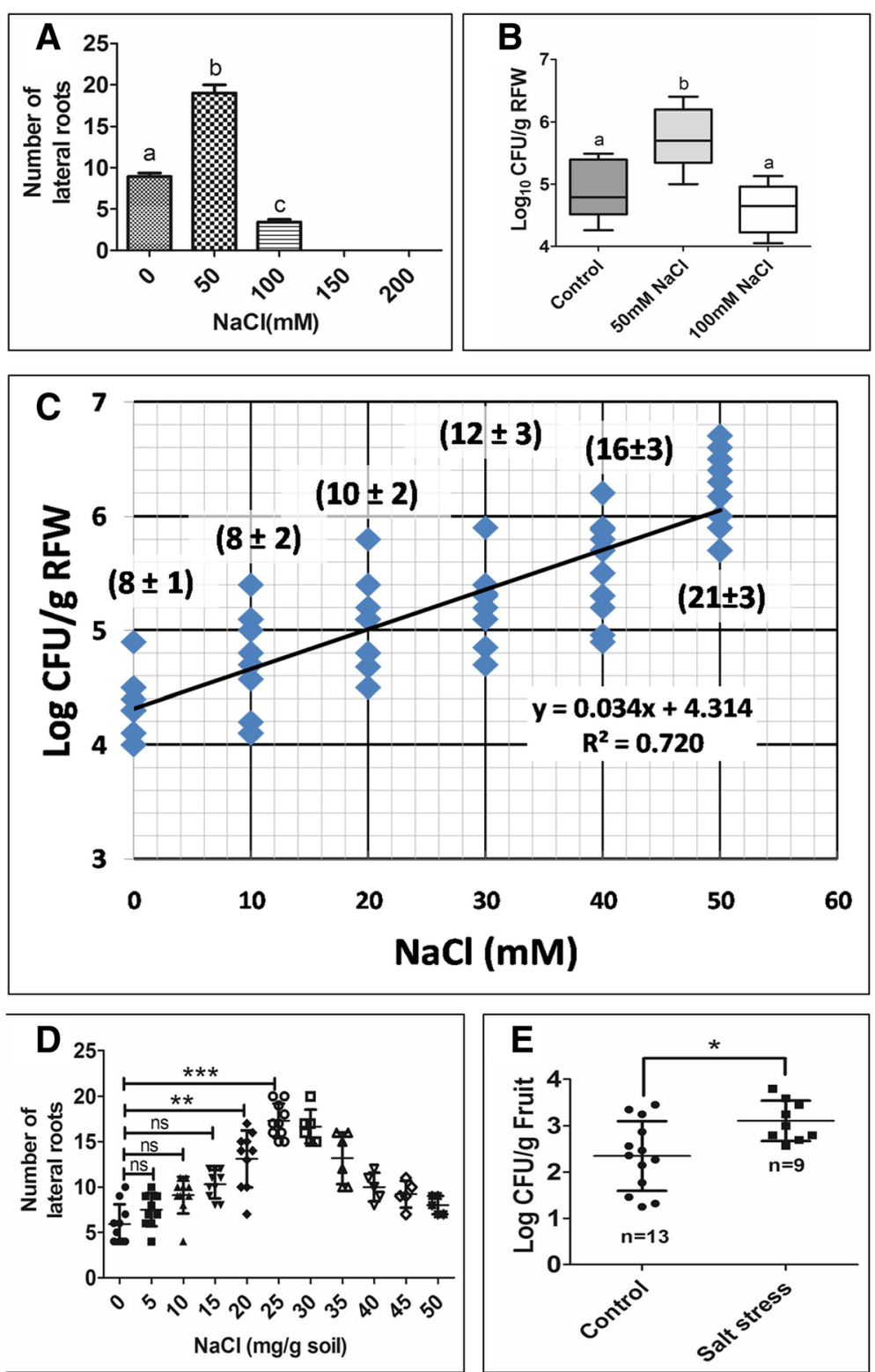

Fig. 3 Salinity renders the plant susceptible to Salmonella. (a) Number of lateral roots upon treatment with varing amount of NaCl. (b) Salmonella colonization on arabidopsis roots treated with $50 \mathrm{mM}$ and $100 \mathrm{mM} \mathrm{NaCl}$. One way ANOVA followed by Bonferroni's post test was used to analyse the data. Different letters shows significance at $P<0.05$. (c) Correlation between salt stress and Salmonella colonization on arabidopsis root (at 95\% CI). The values in parenthesis represent number of lateral root (Mean \pm SD). (d) Number of lateral root of tomato plotted against varying salt stress. One way ANOVA followed by Bonferroni's post test was used to analyse the data. $P<0.001={ }^{* * *}$; ns $=$ not significant. (e) Tomato fruits infected with Salmonella upon mild salinity stress ( $25 \mathrm{mg} \mathrm{NaCl} / \mathrm{g}$ soil; EC $=2.25 \mathrm{dS} / \mathrm{m}$ ). Each experiment was repeated 3 times with 3 replicate each. Mann-Whitney test was used to analyse the data. $P<0.05=*$

non-classical phytopathogens like Salmonella enterica and entero-pathgenic E.coli (O157:H7), colonizes and enter the root tissue via lateral root emerging region [22] and are known to induce defense responses in plants [42, 43]. Though observations were made that lateral root emergence can serve as entry point [22, $25,44]$, the questions regarding the efficacy of the process and specific induction of lateral roots by the pathogen remained unanswered.

Auxin is indispensible for lateral root formation and indeed is a highly regulated developmental process in plants [45]. Lateral root initiation begins with auxin reflux between neighbouring cells and lateral root founder cell (LRFC) in pericycle which is dependent on PIN1 
auxin transporter [30] but its emergence requires co-operation from the neighboring cells like endodermis [31]. This leads to weakening of paracellular junction of endodermis to allow lateral root to cross the endodermis. Local degradation of casparian strip and changes in its mechanical properties allows the lateral root to pass through endodermis [46]. The auxin signal spreads from the lateral root to the cortex and epidermis causing a coordinated remodeling of these layers [32]. We used Arabidopsis mutant axr13 which produces fewer lateral roots, but could be induced to produce lateral root upon treatment with $1000 \mathrm{nM}$ auxin [29]. We observed that irrespective of the number of lateral root, the rhizoplanic colonization remains unaffected. The endophytic population of Salmonella was high for Col-0 as compared to axr1-3 (uninduced). When axr1-3 was treated with $1000 \mathrm{nM}$ NAA, the lateral roots increases significantly confirming that it is only the root tissue population which is dependent on the number lateral root (both in-vitro and in-situ), not the surface population. We screened phytopathogens like Ralstonia solanacearum, Xanthomonas oryzae, Pectobacterium carotovorum and Pseudomonas syringae and found that only P.syringae showed minimal killing of the host when inoculated on root. P.syringae also exibit high rhizoplanic colonization and tissue invasion (Additional file 7: Figure S7). Ralstonia inoculated plants, on the other hand, wilted and died because of the blockage of xylem. Comparatively high survival of P.syringae inoculated plants could be due to the fact that it is a foliar pathogen and root is not the primary site of infection. E.coli treated plants showed 100\% survival and had low epiphytic as well as endophytic colonization (Additional file 7: Figure S7). Therefore, P.syringae was used as a phyto-pathogen control and E.coli as non-phytopathogen control. High correlation of endophytic Salmonella CFU and number of lateral roots $\left(R^{2}=0.729\right.$ at $\left.95 \% C I\right)$ was observed. This implies Salmonella utilize lateral root emergence very efficiently to access the root tissues. In confocal microscopy phytopathogens were found to colonize both lateral root emerging and non-emerging site equally. Unlike Ralstonia solanacearum, the plant pathogen $P$. syringae, which colonize the root without killing the plant, was found to have a lower correlation $\left(R^{2}=0.309\right)$ with lateral root number. This suggests that phytopathogens which use lateral root as an alternative to the active invasion by degrading cell wall. Salmonella solely depends on the lateral roots to access the plant tissue, owing to its inability to degrade the cell wall. Salmonella, E.coli and P.syringae do not trigger the development of new lateral roots which can afftect the correlation. When Col-0 and axr 1-3 were transplanted in the same pot containing Salmonella mixed with soil, we found enrichment of the pathogen in root tissue of Col-0 only. This supports the fact that given equal opportunity to colonize both Col-0 and axr1-3, Salmonella colonization in the root interior depends solely on the lateral root number. Further the presence of Col-0 in vicinity does not affect the colonization of the mutant axr1-3.

Beneficial microbes are known to modulate root growth and development [47]. We use G. diazotrophicus, an endophyte, [48] and P.fluorescence, a rhizospheric bacteria [49] as control organisms to monitor the affect on lateral root development. Treatment of plants with these organisms do not causes mortality (Additional file 7: Figure S7). Nevertheless, unlike these beneficial organisms, Salmonella do not promote lateral root development.

The growth of plants can be affected by various stress factors in soil [50]. Drought, salinity, sodicity, acidity and alkalinity are the major abiotic stresses in soil [51]. Salinity is caused by reduction in water potential due to the accumulation of dissolved ions and can lead to the accumulation of certain metabolites in plants, like glycine betains, proline which act as osmolytes [52]. Overcoming salinity is a challenging problem in agricultural fields. The reasons for salinity developement in soil are - excessive evapo-transpiration, injudicious use of chemical fertilizers, usage of irrigation water containing dissolved salts, etc. In Arabidopsis, mild salinity is known to cause morphogenetic changes in root system [35], however, high salinity is detrimental for the general development of the plant [53]. Decrease in primary root length and secondary root proliferation are well studied in this regard [35]. We chose to work with salinity stress because it promotes lateral root development (Additional file 4: Figure S4), which could be utilized by Salmonella to access entry into the root. Taken together our results suggest that plant roots not only become susceptible to Salmonella invasion but also enhance its transmission to the aerial edible organs. Various environmental and agronomic factors are known to influence the survival of Salmonella in soil like seasonal variation, cultivar, pathovar, residue from previous crop, irrigation regime $[8,54]$. However, much was not know about the soil stress parameters. We, for the first time, tried to correlate the stress factors in soil with the invasiveness of the human pathogen in plants. Salinity induced lateral root proliferation and transmission of Salmonella to the edible organs are novel findings in this regard. Hence, outbreaks due to consumption of raw fruits and vegetables could be attributed to the soil stress factors in addition to climatic, agronomic and plant factors. However, the mechanism by which Salmonella overcomes the soil stress factors is not well understood. We would like to study the tri-partite interaction between Salmonella- plant and soil stress factors in future. Apart from the abiotic factors, biotic factors like Mycorrhiza and other 
PGPRs are also known to cause lateral root proliferation $[27,28]$. We also aim to explore the possibilities of such beneficial organisms in affecting the colonization of Salmonella in roots.

\section{Conclusion}

Pre-harvest contamination of edible plant products occur through soil. Salmonella, a human pathogen, is known to persist for about 300 days in soil [38]. The transmission of pathogen from soil to plant tissue is facilitated by the lateral root emerging areas. The remodeling of epidermis during lateral root emergence creates a cavity which can be utilized by Salmonella to invade the root tissue. This dependence on lateral root is not a general affect because phytopathogens do not solely depend on them, probably because of their ability to degrade cellulosic cell wall of plant. But Salmonella can utilize it as a gateway to access the deeper tissue of the roots, making it an opportunistic organism. It is known that environmental and soil factors can influence the colonization status of Salmonella [8]. Our data suggest that osmotic stress in soil by the dissolved salt can also affect the colonization of Salmonella. Mild salinity can cause morphogenetic changes in root architecture like enhancement of lateral roots, thus making more gateways for the pathogen to enter into the host tissue.

\section{Methods}

Growth conditions for plant and assessment of number of lateral roots

Arabidopsis thaliana ecotype Col-0 and mutant axr 1-3 seeds were surface sterilized $(0.01 \% w / v$ SDS with $70 \%$ $v / \mathrm{v}$ ethanol), placed on Murashige and Skoog (MS) agar plate and stratified for 4 days. The plates were incubated in a growth chamber (Geotech, Korea) with 16/8 h light and dark cycle at $22{ }^{\circ} \mathrm{C}$ and $75 \%$ relative humidity. After 7 days of germination, they were transferred to naphthelene acetic acid (NAA) containing plate $(0,50,100,500$ and $1000 \mathrm{nM})$ and lateral roots were counted after 1 week. Another set of plants (14 days old) were transferred to $\mathrm{NaCl}$ containing plate $(25,50,100,200 \mathrm{mM})$ and assessed for lateral roots after 1 week. Seedlings were transferred to autoclaved potting mixture as and when required. The pots were kept in growth room at $22{ }^{\circ} \mathrm{C} .16 \mathrm{~h}$ light $/ 8 \mathrm{~h}$ dark cycle was used as photoperiod regime with a relative humidity of $75 \%$ and light intensity of $\sim 6000 \mathrm{~lx}$. Pots were irrigated with $15 \mathrm{ml}$ sterile water every day.

\section{Bacterial strains, media, and culture conditions}

Bacteria were plated either on LB medium or LB Supplemented with Ampicilin $(50 \mu \mathrm{g} / \mathrm{ml}$ ) (for Salmonella Typhimurium strain ATCC 14028 and S. Typhimurium expressing GFP/mcherry respectively [55]) from glycerol stocks. Plating onto Salmonella-Shigella agar (SS agar), a semi-selective differential medium, was used to determine S.Typhimurium as and when required. Escheichia coli DH5 $\alpha$ (ATCC) [56], Ralstonia solanacearum strain F1C1 [57], Pectobacterium carotovorum ATCC 15713 and Xanthomonas oryzae pv oryzae strain 189 (kind gift from Prof. R Sonti, NIPGR, India) was grown on LB plates. Ralstonia strain expressing mcherrry (kind gift from Prof. SK Ray, Tezpur University, India) was grown on LB with $50 \mu \mathrm{g} / \mathrm{ml}$ gentamycin. Gluconacetobacter diazotrophicus SO01 (kind gift from Prof. N Earanna, UAS, Bangalore, India) was grown on LGIP media with $10 \%$ sucrose. Pseudomonas syringae pv.tomato DC3000 (ATCC-BAA 871) (kind gift from Prof. R Sonti, NIPGR, India) and Pseudomonas fluorescence ATCC 13525 was grown on King's B medium [58] (kind gift from Prof. N Nagaraj, UAS, Bangalore, India). Bacterial cultures were grown at $30^{\circ} \mathrm{C}(P$. syringae, P.fluorescence, R.solanacearum, $X$. oryzae, G. diazotrophicus, P. carotovorum) for $36 \mathrm{~h}$ or at $37^{\circ} \mathrm{C}$ (S. Typhimurium and E.coli) for $24 \mathrm{~h}$ in plates. Growth curve for S. Typhimurium, P. syringae, R.solanacearum and $X$. oryzae was done in M9 minimal media with $0.3 \%$ cellulose or pectin as sole carbon source.

\section{In-vitro Arabidopsis roots inoculation}

Roots of 14-day old Col-0 or axr 1-3 seedlings were dipped in $10^{8}$ cells $/ \mathrm{ml}$ culture of S.Typhimurium, P.syringae or E.coli and incubated for $72 \mathrm{~h}$ under similar growth conditions. Roots were washed twice with 1X PBS to remove the un-adhered cells and homogenized using $1 \mathrm{~mm}$ glass beads in bead-beader (Biospec MiSci, USA). The suspension was serially diluted and plated on SS agar (for Salmonella and E.coli) or King's B agar (for P. syringae). The CFU was normalized to root fresh weight (RFW).

\section{In-situ plant inoculation through soil}

Salmonella Typhimurium was grown to an optical density $\left(\mathrm{OD}_{600 \mathrm{~nm}}\right)$ of 0.3 , which corresponds to $10^{8} \mathrm{CFU} / \mathrm{ml}$. Cells were centrifuged, re-suspended in 0.5X MS broth (only salt; without sucrose and hormones) and mixed thoroughly with the soil $(1 \mathrm{ml}$ suspension/g soil). The soil was allowed to dry and filled in pots. 10-day old Col-0 and axr 1-3 seedlings were transplanted in these soils. Salmonella burden was assessed in rhizoplane and root tissue after $1,4,7,10,14$ and 20 days by the following procedure: After removal of the soil from the roots, they were put in sterile PBS and vortexed for 20 min to remove the surface-adhered rhizoplanic population. The rhizoplanic suspension was serially diluted and plated to assess the rhizoplanic population (Detailed procedure is mentioned in Additional file 8: Figure S8 and Additional file 9: Figure S9. The same root images before and after vortex are shown in Additional file 8: Figure S8B. The error percentage of the procedure was 
less than 0.001). The roots were immediately taken out from the suspension and crushed using mini bead-beader. The tissue homogenate was serially diluted and plated to assess the root tissue population. The CFU in rhizoplane and root tissue was normalized to root fresh weight (RFW). When surface sterilization of the root was done using $1 \%$ sodium hypochloride for $1 \mathrm{~min}$, the bacteria inside the lateral root emerging region were killed because of the opening present at this area. Therefore, we use mechanical separation of the rhizoplanic population by vortexing. The viability of the bacteria localized inside the lateral root emerging region was confirmed by PI staining (Additional file 8: Figure S8C). This strategy was used only for arabidopsis roots. Due to high mechanical damage to the tomato roots, this method was not used and surface sterilization was performed with $1 \%$ bleach for $1 \mathrm{~min}$. Arabidopsis roots, on the other hand were unharmed and on mechanical damage was observed (Additional file 8: Figure S8B). Invasion index (Log CFU root tissue/ Log CFU Rhizoplane) was calculated and plotted for each time point.

\section{Co-transplantation experiment}

In another set both Col-0 and axr1-3 were co-tran splanted in the same pot pretreated with Salmonella and CFU in tissue was estimated after 20 days. Three such pots were examined and mean CFU of Col- 0 and axr1-3 were plotted. Because of large variations, the experiment was repeated 20 times. One-to-one correlation was plotted with mean CFU in tissue for Col-0 and axr1-3 obtained from each experiment. The paired values are the mean CFUs derived from plants from same pot. Wilcoxan matched pair test was used to analyze the data.

\section{Salinity treatment and Salmonella transmission to aerial organs}

Tomato seeds were surface sterilized (with 1\% bleach and washed with sterile water) and sown in autoclaved nursery soil. The soil in experimental pots was mixed with varying amount of $\mathrm{NaCl}(0,25,50,75$ and $100 \mathrm{mg}$ $\mathrm{NaCl} / \mathrm{g}$ soil). The electrical conductivity was measured using electrical conductivity meter and nursery grown tomato seedlings (20 days old) were transplanted in them. The pots were kept in green house at $26^{\circ} \mathrm{C}$, relative humidity of $70 \%$. Pots were irrigated with $200 \mathrm{ml}$ sterile water every day using micropipette, taking care to avoid splashing of soil and mixing of bacteria. Plants were uprooted carefully after 7 days without harming the root, washed and number of lateral root was counted. In another set soil mixed with $25 \mathrm{mg}$ $\mathrm{NaCl} / \mathrm{g}$ soil was transplanted with 20 days old tomato seedling and Salmonella was added to the soil via irrigation water after 7 days $\left(10^{8} \mathrm{CFU} / 500 \mathrm{ml}\right)$. Plants were allowed to grow either for 1 week or 3 months.
From the 1 week old plants, root were harvested, surface sterilized with $1 \%$ bleach for $1 \mathrm{~min}$, crushed using mortar pastel and the suspension was serially diluted and plated on SS agar to assess the Salmonella burden. From the 3 month old plant, fruit were harvested, surface sterilized with $5 \%$ bleach for $10 \mathrm{~min}$ and assessed for Salmonella burden by crushing using mortar-pastel and plating onto SS agar.

\section{Confocal imaging of roots}

Two weeks old Arabidopsis roots (after 3 days post inoculation) were washed twice with PBS, dipped in propidium iodide or DAPI $(0.01 \mu \mathrm{g} / \mathrm{ml})$ for $2 \mathrm{~min}$. They were again washed with PBS and mounted on a cover slip. For soil grown plants, 5 times washing was done by sterile PBS. Imaging was done by Zeiss confocal microscope (LSM meta710, Zeiss, Germany) and was analysed using ZEN 2009 Light edition software. ZEN 2012 black edition platform was used for creating 3D image. The GFP channel was then subjected to depth coding using the same platform to assess the bacterial signal from various depth of the root tissue (Additional file 3: Figure S3C-D). A boundary enclosing the remodeled epidermis was marked and three regions of interest were chosen (i, ii and iii). The location of the bacteria was analyzed using the rainbow color code with red representing the top layer and blue representing the deepest layer. Each color represents bacterial signal (GFP) from a particular depth. The signals from the enclosed region indicated bacteria inside the remodeled root architecture. Signals from outside the enclosed region are because of the bacteria present along the curvature of the root (Additional file 3: Figure S3D). Whole root imaging was done using Leica SP8 confocal microscope using tile scan. An average of $95 \mathrm{Z}$-stacks $(1 \mu \mathrm{m}$ interval) were taken for individual tiles (each square in Fig. 1a; Additional file 1: Figure S1B, with DIC image). 3D reconstitution and maximum intensity projection was constructed using LAS X software.

\section{Statistical analysis}

To determine whether the average Salmonella populations in root differed between Col-0 and $\operatorname{axr} 1-3$, populations were $\log$ transformed and unpaired t-tests with a Welch correction were performed using Graph Pad Prism. Two-way ANOVA was performed to check the significance for NAA treatment with number of lateral roots and CFU. Linear regression at 95\% confidence interval $(\mathrm{CI})$ was plotted using Graph pad Prism version 7. MATLAB 2016 was used to create scatter plot and generating correlation between CFU and lateral root. $\mathrm{R}^{2}$ $<0.666$ was considered non significant as per Pearson's correlation tables at $P<0.05$ ( $n=50$ for each organism). One way ANOVA followed by Bonferroni's post test was 
used for analyzing time dependent increase in invasion index and for in-vitro Salmonella colonization of arabidopsis under salinity stress. For co-transplantation experiment, the paired mean CFU values from same pot for Col-0 and axr1-3 was plotted and one-to-one correlation was generated with Graph-pad Prism 7. Wilcoxan matched pair test was used to analyze the data. Mann-Whitney test was used for analyzing the CFUs obtained from tomato fruits.

\section{Additional files}

Additional file 1: Figure S1. Growth of bacteria on cellulose and pectin containing media and pattern of colonization on plant roots. (A and B) Growth of Salmonella, Pseudomonas, Ralstonia and Xanthomonas on M9 minimal media with $0.3 \%$ cellulose or pectin as the sole carbon source respectively. Tomato roots inoculated with (C) Ralstonia solanacearum (mcherry), (D) Pseudomonas syringae (GFP), (E) Salmonella Typhimurium (GFP) and R. solanacearum $\triangle$ hrpB (mcherry). Images were taken after 3 days post infection. Propidium iodide and DAPI is used to stain the plant in $(\mathrm{E})$ and $(\mathrm{F})$ respectively. $\operatorname{Pr}=$ Pericycle and $\mathrm{En}=$ Endodermis. The dotted line represents the vasculature. (G) CFU of Salmonella and phytopathogens in rhizoplane and tissue. One way ANOVA was used to analyze the data. Different alphabets represent significance at $p<0.005$. (H) Growth of Salmonella and phyto-pathogens in tomato root exudates. (I) Representative image of Ralstonia solanacearum colonization on arabidopsis. The green arrowhead represents lateral root emerging areas and the white arrowhead represents non emerging areas. Please note that mcherry fluorescence is coming from all over the root (i) specially in the vasculature (ii and iii). (TIF $1310 \mathrm{~kb}$ )

Additional file 2: Figure S2. Induction of lateral root by Naphthalene acetic acid (NAA) and correlation with CFU. (A) NAA concentration dependent decrease or increase in lateral root number in Col-0 and axr 1-3 respectively. ANOVA was used to analyse the data. Different alphabets represent significance at $p<0.005$. Scale bar $=1 \mathrm{~cm}$. (B) Salmonella CFU on roots treated with varying concentration of NAA. (C) Scatter plot showing Pseudomonas syringae CFU inside root tissue with respect to number of lateral roots. (D-F) Scatter plot showing Salmonella (D), E.coli DH5a (E) and Pseudomonas syringae (F) CFU on rhizoplane with respect to number of lateral root. (TIF $603 \mathrm{~kb}$ )

Additional file 3: Figure S3. Epidermis remodeling during lateral root emergence and bacterial colonization. (A) Representative image showing Salmonella entering the gap created between primary root and lateral root during remodeling of epidermis in transverse section. White arrow is representing the cavity. (B) Orthogonal sections showing the gap created in epidermis and bacterial entry in $X-Y, Y-Z$ and $X-Z$ planes. White arrow head shows the site of entry. (C) Representative image showing remodeled epidermis (marked by dotted line) and Salmonella (GFP tagged) cluster inside the region (red arrow head). (D) Depth coding was done only for GFP channel to estimate the location of Salmonella inside the remodeled epidermis. The rainbow color coded chart was used to locate the bacteria at various depth. (i, ii and iii are three region of interest showing bacteria at different depth. PR represents primary root and LR represents lateral root. (TIF $1058 \mathrm{~kb}$ )

Additional file 4: Figure S4. Representative Images for lateral root phenotype for normal and $50 \mathrm{mM} \mathrm{NaCl}$ stress. Values in parenthesis represent number of lateral roots \pm SD. Image was taken by Olympus STYLUS VH520 camera. Newly emerged lateral roots that were very small were observed by Olympus SZX7 stereoscope. (TIF $497 \mathrm{~kb}$ )

Additional file 5: Figure S5. Correlation between varying salt stress in soil with Salmonella colonization in root (at 95\% CI). (TIF $154 \mathrm{~kb}$ )

Additional file 6: Figure S6. Percent fruit infected with Salmonella upon salt stress ( $25 \mathrm{mg} \mathrm{NaCl} / \mathrm{g}$ Soil).and control condition. Student's t-test was used to analyze the data. ${ }^{* * *}=P<0.001 ;{ }^{* *}=P<0.01$. (TIF $88 \mathrm{~kb}$ )
Additional file 7: Figure S7. Parameters studied to chose phytopathogen and non-phyto-pathogen control. (A) Representative image of plant grown in soil inoculated with different bacterial strans. Images were taken by Olympus STYLUS VH520 camera after 7 days of transplantation. (B) CFU of bacteria in the root tissue after 3 days of infection. (C) Survival curve of plants grown on soil mixed with various organisms $(n=60)$. (D) Epiphytic colonization of tomato roots with Salmonella, E.coli and P. syringae. (E) Parameter used for selecting the good colonist and poor colonist for comparison with Salmonella. E.coli was selected as poor colonist whereas P.syringae was used as good colonist. (TIF $1109 \mathrm{~kb}$ )

Additional file 8: Figure S8. Protocol for separation of rhizoplanic bacteria from internalized bacteria. (A) Scematic representation of the protocol for estimating surface colonizing versus the invading bacteria. (B) Representative confocal image of the entire root before and after vortex. Note that these are same root shown before and after vortex. The same region on both the roots are zoomed in (A and B). Vortex above 200RPM leads to mechanical damage to the root. (C and D) Comparison between the viability of bacteria after vortexing and after $1 \%$ sodium hypochloride treatment respectively. Please note that the same root was first imaged after vortexing and then after sodium hypochloride treatment. Arrow head showing the internalized Salmonella. $\mathrm{Ep}=$ Epidermis; Co = Cortex. (TIF $2016 \mathrm{~kb}$ )

Additional file 9: Figure S9. Standardization and verification of time for vortexing procedure for separation of rhizoplanic bacteria. (A) Schematic showing the verification of the process of separation of rhizoplanic population. (B) Minimum time required for vortexing (' $X$ ') the root to isolate the surface adhering population from the rhizoplane. The CFU and the dilution factor are shown for stage 2 (C) Cross examination of the vortexed root (after $20 \mathrm{~min}$ ). The roots were placed in fresh PBS again and vortexed for 5 more min and the suspension was plated. The CFU values at Oth dilution and colonies on plate are shown in table. Plates with colonies between 30 to 300 were counted. (D) Error in the process was calculated by [CFU at stage 2 (at 0th dilution)/(CFU at stage $1+$ stage 2)\} expressed in percentage. Note that $X=20$ min was taken for all organisms. (TIF $459 \mathrm{~kb}$ )

\section{Acknowledgements}

The strain Pseudomonas syringae pv. tomato DC3000 and Xanthomonas oryzae pv. oryzae 189 was a kind gift from Dr. Ramesh Sonti (NIPGR, New Delhi, India). Dr. B.N. Prakash (Dept. of Soil Science and Agril. Chemistry, UAS, Bangalore, India) is acknowledged for Electrical conductivity experiment. Prof. N. Earanna (Dept of Agril. Microbiology, UAS, Bangalore, India) is acknowledged for providing Gluconacetobacter diazotrophicus strain SO-01. Dr. N. Nagaraj (Dept. of Plant pathology, UAS, Bangalore, India) is acknowledged for providing Pseudomonas fluorescence strain. Dr. Suvendra K Roy (Dept of Molecular Biology and Biotechnology, Tezpur University, Assam, India) is acknowledged for proving Ralstonia solanacearum strain F1C1. Departmental and divisional confocal and Central Green House Facility at IISc are acknowledged. Mr. Kapudeep Karmakar is a recipient of IISC Fellowship, which is acknowledged.

\section{Author contributions}

KK, UN, NNK and DC designed the research experiments. KK performed the research, analyse the data and wrote the manuscript. All authors read and approved the final manuscript.

\section{Funding}

This work was supported by the DAE SRC fellowship (DAE00195) and DBTIISc partnership umbrella program for advanced research in biological sciences and Bioengineering to DC. Infrastructure support from ICMR (Centre for Advanced Study in Molecular Medicine), DST (FIST), and UGC (special assistance) is acknowledged. KK acknowledges IISc Fellowship from MHRD, Govt. of India. The funding bodies funded the project based on the merit of the proposal. These funding bodies had no influence over the experimental protocol designing, data analysis or interpretation, or writing the manuscript.

\section{Availability of data and materials}

All data generated or analyzed during this study are included in this article (and its Additional files) or are available from the corresponding author on reasonable request. 


\section{Ethics approval and consent to participate}

All soil inoculation experiments with tomato and Arabidopsis were conducted as per the SOPs decided by Institutional Biosafety Committee (Ref: IBSC/IISC/DC/ 07/2017).

\section{Consent for publication}

Not applicable.

\section{Publisher's Note}

Springer Nature remains neutral with regard to jurisdictional claims in published maps and institutional affiliations.

\section{Author details}

${ }^{1}$ Department of Microbiology and Cell Biology, Indian Institute of Science, Bangalore 560012, India. ${ }^{2}$ Centre for Biosystems Science and Engineering, Indian Institute of Science, Bangalore 560012, India. ${ }^{3}$ Department of Crop Physiology, University of Agricultural Science, GKVK, Bangalore 560065, India.

\section{Received: 29 March 2018 Accepted: 29 November 2018}

\section{Published online: 11 December 2018}

\section{References}

1. Olsen JE, Sørensen M, Brown DJ, Gaarslev K, Bisgaard M. Plasmid profiles as an epidemiological marker in Salmonella enterica serovar Berta infections. Comparison of isolates obtained from humans and poultry. APMIS. 1992;100:221-8.

2. Baggesen DL, Wegener HC. Phage types of Salmonella enterica ssp. enterica serovar typhimurium isolated from production animals and humans in Denmark. Acta Vet Scand. 1994;35(4):349-54

3. Sivapalasingam S, Barrett E, Kimura A, Van Duyne S, De Witt W, Ying M, Frisch A, Phan Q, Gould E, Shillam P, et al. A multistate outbreak of Salmonella enterica serotype Newport infection linked to mango consumption: impact of water-dip disinfestation technology. Clinical infectious diseases : an official publication of the Infectious Diseases Society of America. 2003;37(12):1585-90.

4. Ward LR, Maguire C, Hampton MD, de Pinna E, Smith HR, Little CL, Gillespie IA, O'Brien SJ, Mitchell RT, Sharp C, et al. Collaborative investigation of an outbreak of Salmonella enterica serotype Newport in England and Wales in 2001 associated with ready-to-eat salad vegetables. Commun Dis Public Health. 2002;5(4):301-4

5. CDC: https://www.cdc.gov/salmonella/outbreaks.html. In.: CDC; 2013-2017.

6. Van Doren JM, Blodgett RJ, Pouillot R, Westerman A, Kleinmeier D, Ziobro GC, Ma Y, Hammack TS, Gill V, Muckenfuss MF, et al. Prevalence, level and distribution of Salmonella in shipments of imported capsicum and sesame seed spice offered for entry to the United States: observations and modeling results. Food Microbiol. 2013;36(2):149-60.

7. Greene SK, Daly ER, Talbot EA, Demma LJ, Holzbauer S, Patel NJ, Hill TA, Walderhaug MO, Hoekstra RM, Lynch MF, et al. Recurrent multistate outbreak of Salmonella Newport associated with tomatoes from contaminated fields, 2005. Epidemiol. Infect. 2008:136(2):157-65.

8. Marvasi M, Hochmuth GJ, Giurcanu MC, George AS, Noel JT, Bartz J, Teplitski M. Factors that affect proliferation of Salmonella in tomatoes post-harvest: the roles of seasonal effects, irrigation regime, crop and pathogen genotype. PLoS One. 2013;8(12):e80871.

9. Barak JD, Liang A, Narm KE. Differential attachment to and subsequent contamination of agricultural crops by Salmonella enterica. Appl Environ Microbiol. 2008;74(17):5568-70.

10. Barak JD, Liang AS. Role of soil, crop debris, and a plant pathogen in Salmonella enterica contamination of tomato plants. PLoS One. 2008:3(2):e1657.

11. Berger CN, Shaw RK, Brown DJ, Mather H, Clare S, Dougan G, Pallen MJ, Frankel G. Interaction of Salmonella enterica with basil and other salad leaves. The ISME journal. 2009;3(2):261-5.

12. Barak JD, Gorski L, Naraghi-Arani P, Charkowski AO. Salmonella enterica virulence genes are required for bacterial attachment to plant tissue. Appl Environ Microbiol. 2005;71(10):5685-91.

13. Barak JD, Jahn CE, Gibson DL, Charkowski AO. The role of cellulose and Oantigen capsule in the colonization of plants by Salmonella enterica. Molecular plant-microbe interactions : MPMI. 2007:20(9):1083-91.

14. Potnis N, Soto-Arias JP, Cowles KN, van Bruggen AH, Jones JB, Barak JD. Xanthomonas perforans colonization influences Salmonella enterica in the tomato phyllosphere. Appl Environ Microbiol. 2014;80(10):3173-80.
15. Hernandez-Reyes C, Schenk ST, Newman C, K. H K, Schikora A. N-acylhomoserine lactones-producing bacteria protect plants against plant and human pathogens. Microb Biotechnol. 2014;7(6):580-8.

16. Gu G, Hu J, Cevallos-Cevallos JM, Richardson SM, Bartz JA, van Bruggen AH. Internal colonization of Salmonella enterica serovar typhimurium in tomato plants. PLoS One. 2011;6(11):e27340.

17. Kroupitski Y, Golberg D, Belausov E, Pinto R, Swartzberg D, Granot D, Sela S. Internalization of Salmonella enterica in leaves is induced by light and involves chemotaxis and penetration through open stomata. Appl Environ Microbiol. 2009;75(19):6076-86.

18. Gu G, Cevallos-Cevallos JM, van Bruggen AH. Ingress of Salmonella enterica typhimurium into tomato leaves through hydathodes. PLoS One. 2013;8(1): e53470.

19. Gautam D, Dobhal S, Payton ME, Fletcher J, Ma LM. Surface survival and internalization of Salmonella through natural cracks on developing cantaloupe fruits, alone or in the presence of the melon wilt pathogen Erwinia tracheiphila. PLoS One. 2014;9(8):e105248.

20. Gorbatsevich E, Sela Saldinger S, Pinto R, Bernstein N. Root internalization, transport and in-planta survival of Salmonella enterica serovar Newport in sweet basil. Environ Microbiol Rep. 2013;5(1):151-9.

21. Lopez-Velasco G, Sbodio A, Tomas-Callejas A, Wei P, Tan KH, Suslow TV. Assessment of root uptake and systemic vine-transport of Salmonella enterica sv. Typhimurium by melon (Cucumis melo) during field production. Int J Food Microbiol. 2012;158(1):65-72

22. Cooley MB, Miller WG, Mandrell RE. Colonization of Arabidopsis thaliana with Salmonella enterica and enterohemorrhagic Escherichia coli O157:H7 and competition by Enterobacter asburiae. Appl Environ Microbiol. 2003; 69(8):4915-26.

23. Sørensen J, Sessitsch A: Plant-associated bacteria lifestyle and molecular interactions, 2 edn: CRC press, 2006; 2015

24. Gutjahr C, Casieri L, Paszkowski U. Glomus intraradices induces changes in root system architecture of rice independently of common symbiosis signaling. New Phytol. 2009;182:829-37.

25. Klerks MM, van Gent-Pelzer M, Franz E, Zijlstra C, van Bruggen AH. Physiological and molecular responses of Lactuca sativa to colonization by Salmonella enterica serovar Dublin. Appl Environ Microbiol. 2007:73(15):4905-14.

26. Bellincampi D, Cervone F, Lionetti V. Plant cell wall dynamics and wall-related susceptibility in plant-pathogen interactions. Front Plant Sci. 2014;5:228.

27. Gutjahr C, Paszkowski U. Multiple control levels of root system remodeling in arbuscular mycorrhizal symbiosis. Front Plant Sci. 2013;4.

28. Vacheron J, Desbrosses G, Bouffaud ML, Touraine B, Moenne-Loccoz Y, Muller D, Legendre L, Wisniewski-Dye F, Prigent-Combaret C. Plant growth-promoting rhizobacteria and root system functioning. Front Plant Sci. 2013;4:356.

29. Celenza JL Jr, Grisafi PL, Fink GR. A pathway for lateral root formation in Arabidopsis thaliana. Genes Dev. 1995:9(17):2131-42.

30. Marhavy P, Vanstraelen M, De Rybel B, Zhaojun D, Bennett MJ, Beeckman T, Benkova E. Auxin reflux between the endodermis and pericycle promotes lateral root initiation. EMBO J. 2013;32(1):149-58

31. Vermeer JE, von Wangenheim D, Barberon $M$, Lee $Y$, Stelzer EH, Maizel A, Geldner N. A spatial accommodation by neighboring cells is required for organ initiation in Arabidopsis. Science. 2014;343(6167):178-83.

32. Vilches-Barro A, Maizel A. Talking through walls: mechanisms of lateral root emergence in Arabidopsis thaliana. Curr Opin Plant Biol. 2015;23:31-8.

33. Peret B, Larrieu A, Bennett MJ. Lateral root emergence: a difficult birth. J Exp Bot. 2009:60(13):3637-43.

34. Zolla G, Heimer YM, Barak S. Mild salinity stimulates a stress-induced morphogenic response in Arabidopsis thaliana roots. J Exp Bot. 2010;61:211-24.

35. Julkowska MM, Hoefsloot HCJ, Mol S, Feron R, de Boer GJ, Haring MA, Testerink C. Capturing Arabidopsis Root Architecture Dynamics with ROOT-FIT Reveals Diversity in Responses to Salinity. Plant Physiol. 2014;166:1387-402.

36. Xu H, Qin F, Gautheir L, Gosselin A. Green house tomato growth and physiological responses to high nutrient solution and electrical conductivity and low substrate water content. Fruits, Vegetables and Cereals Science and. Biotechnology. 2009;3:54-61.

37. Park S, Szonyi B, Gautam R, Nightingale K, Anciso J, Ivanek R. Risk factors for microbial contamination in fruits and vegetables at the preharvest level: a systematic review. J Food Prot. 2012;75(11):2055-81.

38. Baloda SB, Christensen L, Trajcevska S. Persistence of a Salmonella enterica serovar typhimurium DT12 clone in a piggery and in agricultural soil amended with Salmonella-contaminated slurry. Appl Environ Microbiol. 2001;67(6):2859-62. 
39. Poussier S, Prior P, Luisetti J, Hayward C, Fegan M. Partial sequencing of the hrpB and endoglucanase genes confirms and expands the known diversity within the Ralstonia solanacearum species complex. Syst Appl Microbiol. 2000;23(4):479-86.

40. Xia T, Li Y, Sun D, Zhuo T, Fan X, Zou H. Identification of an extracellular endoglucanase that is required for full virulence in Xanthomonas citri subsp. citri. PLoS One. 2016;11(3):e0151017.

41. Tans-Kersten J, Guan Y, Allen C. Ralstonia solanacearum pectin methylesterase is required for growth on methylated pectin but not for bacterial wilt virulence. Appl Environ Microbiol. 1998;64(12):4918-23.

42. Roy D, Panchal S, Rosa BA, Melotto M. Escherichia coli O157:H7 induces stronger plant immunity than Salmonella enterica typhimurium SL1344. Phytopathology. 2013;103(4):326-32.

43. Garcia AV, Charrier A, Schikora A, Bigeard J, Pateyron S, de Tauzia-Moreau ML, Evrard A, Mithofer A, Martin-Magniette ML, Virlogeux-Payant I, et al. Salmonella enterica flagellin is recognized via FLS2 and activates PAMPtriggered immunity in Arabidopsis thaliana. Mol Plant. 2014;7(4):657-74.

44. Klerks MM, Franz E, van Gent-Pelzer M, Zijlstra C, van Bruggen AH. Differential interaction of Salmonella enterica serovars with lettuce cultivars and plant-microbe factors influencing the colonization efficiency. The ISME journal. 2007;1(7):620-31.

45. Lavenus J, Goh T, Roberts I, Guyomarc'h S, Lucas M, De Smet I, Fukaki H, Beeckman T, Bennett M, Laplaze L. Lateral root development in Arabidopsis: fifty shades of auxin. Trends Plant Sci. 2013;18(8):450-8.

46. Lucas M, Kenobi K, von Wangenheim D, Vobeta U, Swarup K, De Smet I, Van Damme D, Lawrence T, Peret B, Moscardi E, et al. Lateral root morphogenesis is dependent on the mechanical properties of the overlaying tissues. Proc Natl Acad Sci U S A. 2013;110(13):5229-34.

47. Ortiz-Castro R, Contreras-Cornejo HA, Macias-Rodriguez L, Lopez-Bucio J. The role of microbial signals in plant growth and development. Plant Signal Behav. 2009:4(8):701-12.

48. De Souza AR, De Souza SA, De Oliveira MW, Ferraz TM, Figueiredo FAMMA, Da Silva ND, Rangel PL, Panisset CRS, Olivares FL, Campostrini E, et al. Endophytic colonization of Arabidopsis thaliana by Gluconacetobacter diazotrophicus and its effect on plant growth promotion, plant physiology, and activation of plant defense. Plant Soil. 2016;399(1-2):257-70.

49. Rainey PB. Adaptation of Pseudomonas fluorescens to the plant rhizosphere. Environ Microbiol. 1999;1(3):243-57.

50. Brady NC, Weil RR. The nature and properties of soils. In: Pearson Education: 2016.

51. Pereira A. Plant abiotic stress challenges from the changing environment. Front Plant Sci. 2016;7.

52. Karmakar K, Rana A, Rajwar A, Sahgal M, Johri BN. Legume-Rhizobia Symbiosis Under Stress. India: Springer India; 2015.

53. Munns R, Tester M. Mechanisms of salinity tolerance. Annu Rev Plant Biol. 2008:59:651-81.

54. Jacobsen CS, Bech TB. Soil survival of Salmonella and transfer to freshwater and fresh produce. Food Res Int. 2012:45:557-66.

55. Srinandan CS, Elango M, Gnanadhas DP, Chakravortty D. Infiltration of matrix-non-producers weakens the Salmonella biofilm and impairs its antimicrobial tolerance and pathogenicity. Front Microbiol. 2015;6.

56. Balakrishnan A, Chakravortty D. Epithelial cell damage activates bactericidal/ permeability increasing-protein (BPI) expression in intestinal epithelium. Front Microbiol. 2017;8.

57. Ray SK, Kumar R, Peeters N, Boucher C, Genin S. rpoN1, but not rpoN2, is required for twitching motility, natural competence, growth on nitrate, and virulence of Ralstonia solanacearum. Front Microbiol. 2015;6:229.

58. Worley JN, Russell AB, Wexler AG, Bronstein PA, Kvitko BH, Krasnoff SB, Munkvold KR, Swingle B, Gibson DM, Collmer A. Pseudomonas syringae pv. Tomato DC3000 CmaL (PSPTO4723), a DUF1330 family member, is needed to produce L-Allo-isoleucine, a precursor for the phytotoxin coronatine. J Bacteriol. 2013;195(2):287-96.

Ready to submit your research? Choose BMC and benefit from:

- fast, convenient online submission

- thorough peer review by experienced researchers in your field

- rapid publication on acceptance

- support for research data, including large and complex data types

- gold Open Access which fosters wider collaboration and increased citations

- maximum visibility for your research: over $100 \mathrm{M}$ website views per year

At BMC, research is always in progress.

Learn more biomedcentral.com/submissions 